\title{
Longer application of kinesio taping would be beneficial for exercise-induced muscle damage
}

\author{
Jooyoung Kim, Seunghwan Kim, Joohyung Lee* \\ Sport, Health and Rehabilitation Major, College of Physical Education, Kookmin University, Seoul, Korea
}

Kinesio taping (KT) has been widely used to prevent muscle pain and to improve range of motion in clinical settings. However, no previous research has examined how long KT should be applied to muscle following damaging exercise. The aim of this study was to investigate the effect of the duration of KT application on markers of muscle damage following eccentric exercise. Thirty-two male subjects participated in the study and were randomly assigned to one of the following groups: control (CON), KT-post, KT-30 min, or KT-24 hr. Eccentric exercise consisted of 2 sets of 25 contractions of elbow flexors using the non-dominant arm. Maximal isometric strength, muscle soreness (SOR), range of mo- tion, and creatine kinase activity were measured before,immediately after, and at 24, 48, 72, and $96 \mathrm{hr}$ after exercise. The KT-24 hr group showed lesser muscle damage and a faster recovery time than the CON and KT-post groups. Both the KT-30 min and KT-24 hr groups showed lesser SOR than CON and KT-post groups. These findings suggested that prolonged application of KT had a positive effect on markers of muscle damage.

Keywords: Eccentric exercise, Kinesio taping, Muscle damage

\section{INTRODUCTION}

It is well known that strenuous physical activity or excessive eccentric exercise may cause muscle damage (Proske and Morgan, 2001). Muscle damage may lead to decreased muscle strength and range of motion (ROM), delayed onset of muscle soreness (DOMS), as well as increased blood level of muscle enzyme such as creatine kinase (CK), through efflux across the cell membrane (Clarkson and Sayers, 1999). Several interventions are reported to help in reducing the markers of muscle damage after eccentric exercise (Connolly et al., 2003; Trombold et al., 2011; Veqar and Imtiyaz, 2014).

In the 1970s, kinesio taping (KT) was developed by Dr. Kenso Kase in Japan to treat muscle pain and arthritis (García-Muro et al., 2010; Kase et al., 2003; Williams et al., 2012). When KT is applied to the muscle, in which the tape lifts the surface of skin and forms a wide space between the skin and the muscle, resulting in increased blood and lymph flow (Yoshida and Kahanov,
2007). Additionally, the use of KT has been proposed for the maintenance of function by promoting proprioception in the skeletal muscle, for reducing pain by stimulating the neurological system, and for realigning joint movement, by recovering muscle tension (Fu et al., 2008; Huang et al., 2011).

Recently, several studies investigated the effect of KT on muscle damage after exercise. Lee et al. (2015) reported that KT decreases DOMS and promotes faster recovery of muscle strength compared to no KT following eccentric exercise in healthy males. In contrast, Ozmen et al. (2016) suggested that KT application immediately before squat exercise had no effect on muscle pain compared to no KT applicationin young adult females. However, Lee et al. (2015) did not mention when and how long KT was applied, while Ozmen et al. (2016) did not use conventional muscle damage protocol and measure other markers of muscle damage. Additionally, no studies have investigated how long KT should be applied to prevent or treat muscle damage following damaging exercise. Therefore, the purpose of the study was to investigate
${ }^{*}$ Corresponding author: Joohyung Lee (iD http://orcid.org/0000-0001-8279-3830 Sport, Health and Rehabilitation Major, Kookmin University, 77, Jeongneung-ro, Seongbuk-gu, Seoul 02707, Korea

Tel.: +82-2-910-5254, Fax: +82-2-910-4789, E-mail: jolee@kookmin.ac.kr Received: July 28, 2016 / Accepted: September 24, 2016
This is an Open Access article distributed under the terms of the Creative Commons Attribution Non-Commercial License (http://creativecommons.org/licenses/by-nc/4.0/) which permits unrestricted non-commercial use, distribution, and reproduction in any medium, provided the original work is properly cited. 
whether prolonged application of KT has effect on markers of muscle damage following eccentric exercise.

\section{MATERIALS AND METHODS}

\section{Participants}

We enrolled 32 collegiate male subjects between the ages of 21-30 who had not participated in any exercise programs within the past 6 months, were not diagnosed with any neuromuscular diseases, and had not received medications, including nonsteroidal anti-inflammatory drugs. Each subject was randomly assigned to one of the following groups: control group without KT during and after exercise (CON), KT application during exercise and removal immediately after exercise (KT-post), KT application during exercise and removal $30 \mathrm{~min}$ after exercise (KT-30 min), or KT application during exercise and removal $24 \mathrm{hr}$ after exercise (KT-24 hr). Characteristics of subjects are shown in Table 1.

\section{Procedure}

On the first visit, each subject was explained in detail the procedures of the study, prior to signing an informed consent approved by the Institutional Review Board, Kookmin University, Seoul, Korea. Subjects also completed a brief medical history questionnaire. On the second visit, after at least $8 \mathrm{hr}$ of overnight fasting, subjects returned to the laboratory to obtain baseline measurements and perform the eccentric exercise protocol. The baseline measurements include maximal isometric strength (MIS), muscle soreness (SOR), ROM, and serum CK activity. Immediately after exercise, only MIS and ROM were assessed. On the third visit ( $24 \mathrm{hr}$ after exercise), subjects returned to the laboratory for another set of measurements, including MIS, SOR, ROM, and serum CK activity. During fourth to sixth visits, subjects underwent the same measurements. All measurements were taken for each subject, at the same time of the day.

Table 1. Characteristics of subjects

\begin{tabular}{lrrrr} 
Characteristic & $\begin{array}{r}\text { CON } \\
(\mathrm{n}=8)\end{array}$ & $\begin{array}{c}\text { KT-post } \\
(\mathrm{n}=8)\end{array}$ & $\begin{array}{c}\text { KT-30 min } \\
(\mathrm{n}=8)\end{array}$ & $\begin{array}{c}\text { KT-24 hr } \\
(\mathrm{n}=8)\end{array}$ \\
\hline Age $(\mathrm{yr})$ & $25.0 \pm 2.0$ & $24.1 \pm 2.6$ & $27.0 \pm 2.7$ & $25.0 \pm 3.0$ \\
Height $(\mathrm{cm})$ & $174.2 \pm 3.5$ & $174.6 \pm 5.8$ & $175.3 \pm 4.1$ & $179.1 \pm 4.7$ \\
Weight $(\mathrm{kg})$ & $71.1 \pm 5.7$ & $70.3 \pm 6.2$ & $72.2 \pm 6.0$ & $73.5 \pm 9.1$ \\
\hline
\end{tabular}

Values are presented as mean \pm standard deviation.

$\mathrm{KT}$, kinesio taping; CON, control group without $\mathrm{KT}$ during and after exercise; KTpost, KT application during exercise and removal immediately after exercise; $K T-30$ min, KT application during exercise and removal 30 min after exercise; KT-24 hr, KT application during exercise and removal $24 \mathrm{hr}$ after exercise.

\section{Eccentric exercise protocol}

A modified preacher curl machine was used to induce muscle damage (Clarkson et al., 2005; Sayers and Clarkson, 2003). Each subject resisted the investigator while lowering a bar attached to the preacher curl. Each subject performed 2 sets of 25 eccentric contractions with 5 -min rest between sets. These exercises involved the elbow flexors for the nondominant armeach contraction lasted for $3 \mathrm{sec}$, with 12-sec rest between contractions. To make sure that each subject performed voluntarily the maximal contraction, the investigator encouraged to resist maximally when the lever is lowered.

\section{KT application}

Prior to eccentric exercise, Y-shaped KT (width, $5 \mathrm{~cm}$; length, $20 \mathrm{~cm}$ ) was applied to the nondominant arm of each subject (Kinesio Tex, Nitto Denko, Japan). The application of KT was used as described in Kase et al. (2003). While each subject maintained his elbow at $45^{\circ}$, palm upward, the lower part of the Y-shaped tape was attached to the front of the elbow. Each subject was then asked to straighten the elbow, and the upper side of the Y-shaped taping was attached to the biceps.

\section{Maximal isometric strength}

MIS was measured using a strain gauge (Jackson Strength Evaluation System Model. 32628CTL, Lafayette Instrument Co., Lafayette, IN, USA) attached to a modified preacher curl machine (Clarkson et al., 2005). Each subject performed maximal isometric contraction of elbow flexors, using the nondominant arm, while sitting on the preacher curl machine. During each 3-sec contraction, subjects maintained their arm at $90^{\circ}$ and pulled the pad attached to the preacher curl machine. The resting period between measurements was $1 \mathrm{~min}$. To ensure that each subject performed in the same position, the investigator measured joint angle at $90^{\circ}$ with a goniometer (S29-5900, KASCO, Islamabad, Pakistan) and marked the line on the pad attached to the elbow joint each time. Three trials were performed and averaged to determinethe MIS.

\section{Muscle soreness}

SOR was measured using a visual analog scale (VAS), where 0 indicated no soreness and 10 indicated severe soreness (Lau et al., 2015; Nicol et al., 2015). The subjects were asked to draw a vertical line on the scale to indicate how they felt when their exercised arm was in the resting position, following active movements of the elbow joint of exercised arm. 


\section{Range of motion}

Both, the relaxed arm andflexed arm angles were measured using a goniometer and ROM was calculated by subtracting the flexed arm angle from the relaxed arm angle (Gleeson et al., 2003; Howatson et al., 2012). Three trials were performed and averaged to determine ROM.

\section{CK activity}

Blood samples were taken from the antecubital vein using a collection tube (BD Vacutainer, BD Plymouth, Plymouth, UK) and were stored at room temperature for $20 \mathrm{~min}$, in orderto obtainserum. They were then centrifuged at 3,000 rpm for $10 \mathrm{~min}$, and the serum was pipetted and separated into a $1.5-\mathrm{mL}$ microtube (MCT-150-C, Axygen, a subsidary of Corning, New York, NY, USA). Each sample was stored at $-80^{\circ} \mathrm{C}$ for analysis of CK activity using an automated analyzer (Vitros DT60 II, Johnson \& Johnson, Minneapolis, MN, USA).

\section{Statistical analysis}

All values analyzed by descriptive analysis are presented as mean \pm standard deviation. A repeated analysis of variance test analysis of variance was used to detect group-by-time interactions ( $2 \times 6$ for MIS and ROM, $2 \times 5$ for SOR and CK activity) using a IBM SPSS ver. 18.0 (IBM Co., Armonk, NY, USA). Tukey post boc test was used when a significant difference was found. The level of

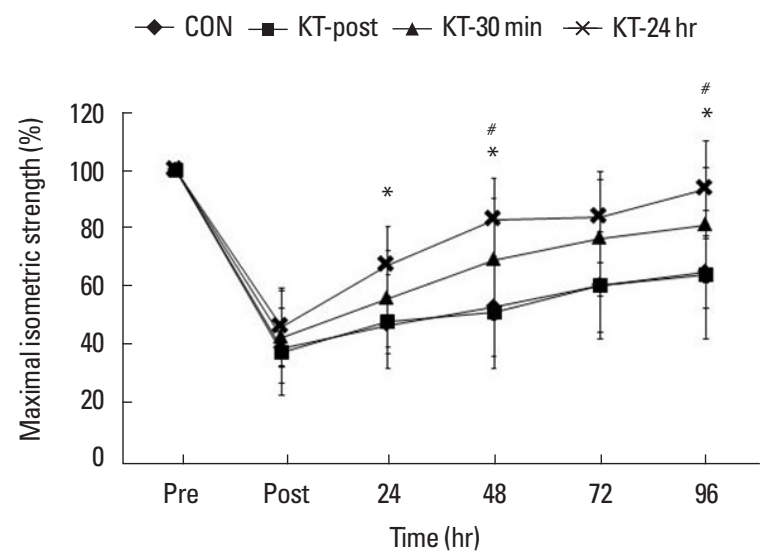

Fig. 1. Changes in maximal isometric strength following eccentric exercise. KT, kinesio taping; Pre, before exercise; Post, immediately after exercise; CON, no KT application during and after exercise; KT-post, KT application during exercise and removal immediately after exercise; KT-30 min, KT application during exercise and removal 30 min after exercise; KT-24 hr, KT application during exercise and removal $24 \mathrm{hr}$ after exercise. Values are mean \pm standard deviation. ${ }^{*} \mathrm{KT}-24 \mathrm{hr}$ showed greater maximal isometric strength (MIS) at 24, 48, and 96 hr after exercise compared to CON $(P<0.05)$. " KT-24 hr showed greater MIS at $48(P<0.01)$ and $96 \mathrm{hr}(P<0.05)$ after exercise compared to KT-post. significance was set at $\alpha<0.05$.

\section{RESULTS}

\section{Maximal isometric strength}

There were significant group-by-time interactions with MIS ( $F=$ $1.873, P=0.042)$ as shown in Fig. 1. All groups showed a significant reduction in MIS immediately after exercise $(P<0.001)$. The KT-24 hr showed a faster recovery at $24 \mathrm{hr}$ (KT-24 hr 67.5\% \pm $13.2 \%$ vs. CON $47.1 \% \pm 10.0 \%, P=0.036), 48 \mathrm{hr}(\mathrm{KT}-24 \mathrm{hr}$ $83.0 \% \pm 14.0 \%$ vs. CON $53.2 \% \pm 16.7 \%, P=0.012)$, and $96 \mathrm{hr}$ (KT-24 hr $93.3 \% \pm 16.8 \%$ vs. CON $65.2 \% \pm 12.4 \%, P=0.021$ ) after exercise compared to CON. In addition, the KT-24 hr showed significant differences at $48 \mathrm{hr}$ (KT-24 hr $83.0 \% \pm 14.0 \%$ vs. CON $51.5 \% \pm 19.2 \%, P=0.008)$ and $96 \mathrm{hr}(\mathrm{KT}-24 \mathrm{hr} 93.3 \% \pm$ $16.8 \%$ vs. CON $64.3 \% \pm 22.0 \%, P=0.016)$ after exercise compared to KT-post.

\section{Muscle soreness}

There were significant group-by-time interactions with SOR $(F=2.112, P=0.028)$ as shown in Fig. 2. A significant reduction in KT-24 hr was noticed at $48 \mathrm{hr}(\mathrm{KT}-24 \mathrm{hr} 2.6 \pm 1.6 \mathrm{~cm}$ vs. CON $5.7 \pm 1.8 \mathrm{~cm}, P=0.026), 72 \mathrm{hr}(\mathrm{KT}-24 \mathrm{hr} 1.7 \pm 1.4 \mathrm{~cm}$ vs.

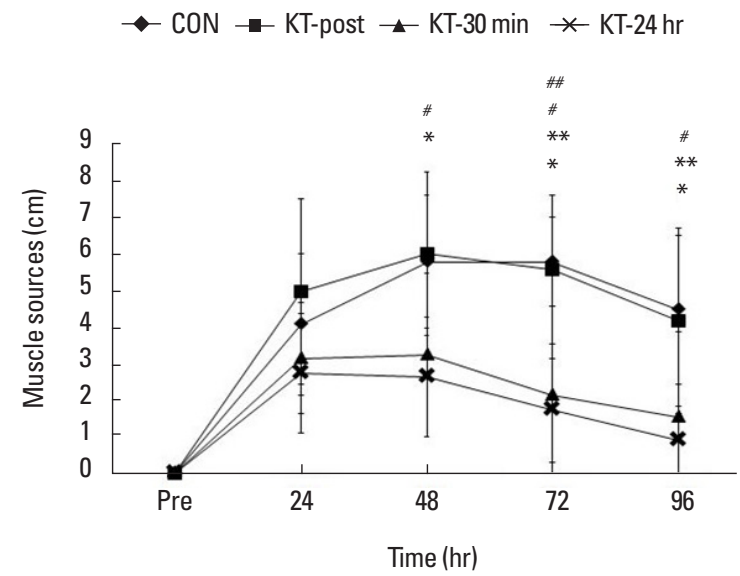

Fig. 2. Changes in muscle soreness following eccentric exercise. Pre, before exercise; CON, no KT application during and after exercise; KT-post, KT application during exercise and removal immediately after exercise; KT-30 min, KT application during exercise and removal 30 min after exercise; KT-24 hr, KT application during exercise and removal $24 \mathrm{hr}$ after exercise. Values are mean \pm standard deviation. ${ }^{*} \mathrm{KT}-24 \mathrm{hr}$ showed lower muscle soreness (SOR) at 48 $(P<0.05), 72(P<0.01)$, and 96hrs $(P<0.05)$ after exercise compared to CON. **KT-30 min showed lower SOR at $72(P<0.01)$, and $96 \mathrm{hr}(P<0.05)$ after exercise compared to CON. ${ }^{~} \mathrm{KT}$-24 hr showed lower SOR at $48(P<0.05), 72$ $(P<0.01)$, and $96 \mathrm{hr}(P<0.05)$ after exercise compared to KT-post. ${ }^{\#} \mathrm{~K} T-30 \mathrm{~min}$ showed lower SOR at $72 \mathrm{hr}(P<0.01)$ after exercise compared to KT-post. 


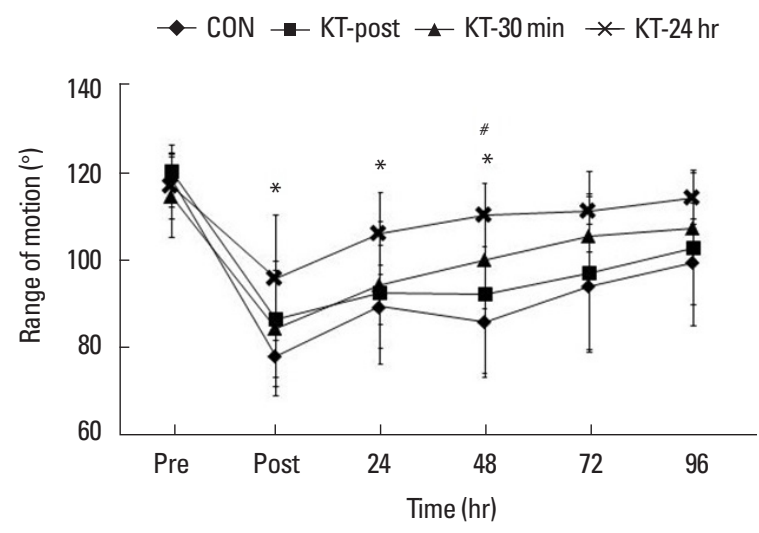

Fig. 3. Changes in range of motion following eccentric exercise. Pre, before exercise; Post, immediately after exercise; CON, no KT application during and after exercise; KT-post, KT application during exercise and removal immediately after exercise; KT-30 min, KT application during exercise and removal 30 min after exercise; $\mathrm{KT}-24 \mathrm{hr}$, KT application during exercise and removal $24 \mathrm{hr}$ after exercise. Values are mean \pm standard deviation. ${ }^{*} \mathrm{KT}-24 \mathrm{hr}$ showed greater range of motion (ROM) at post and $24(P<0.05)$, and $48 \mathrm{hr}(P<0.01)$ after exercise compared to CON. ${ }^{*} \mathrm{KT}-24 \mathrm{hr}$ showed greater ROM at $48 \mathrm{hr}(P<0.05)$ after exercise compared to KT-post.

CON $5.7 \pm 1.2 \mathrm{~cm}, P=0.001)$, and $96 \mathrm{hr}(\mathrm{KT}-24 \mathrm{hr} 0.9 \pm 0.9 \mathrm{~cm}$ vs. $\mathrm{CON} 4.4 \pm 2.0 \mathrm{~cm}, P=0.01$ ) after exercise, when compared to that in CON, while there were significant differences at $48 \mathrm{hr}$ (KT-24 hr 2.6 $\pm 1.6 \mathrm{~cm}$ vs. KT-post $5.9 \pm 2.2 \mathrm{~cm}, P=0.013$ ), 72 hr (KT-24 hr $1.7 \pm 1.4 \mathrm{~cm}$ vs. KT-post $5.5 \pm 2.0 \mathrm{~cm}, P=0.002)$, and $96 \mathrm{hr}(\mathrm{KT}-24 \mathrm{hr} 0.9 \pm 0.9 \mathrm{~cm}$ vs. KT-post $4.1 \pm 2.5 \mathrm{~cm}$, $P=0.019)$ when compared to KT-post. Additionally, KT-30 min showed significant differences at $72 \mathrm{hr}$ (KT-30 $\min 2.1 \pm 2.4 \mathrm{~cm}$ vs. $\mathrm{CON} 5.7 \pm 1.2 \mathrm{~cm}, P=0.003)$ and $96 \mathrm{hr}(\mathrm{KT}-30 \mathrm{~min} 1.5 \pm 2.3$ $\mathrm{cm}$ vs. $\mathrm{CON} 4.4 \pm 2.0 \mathrm{~cm}, P=0.04$ ) after exercise when compared to $\mathrm{CON}$, while a significant difference at $72 \mathrm{hr}$ (KT-30 min $2.1 \pm 2.4 \mathrm{~cm}$ vs. KT-post $5.5 \pm 2.0 \mathrm{~cm}, P=0.005)$ after exercise was identified, when compared to KT-post.

\section{Range of motion}

There were significant group-by-time interactions with ROM $(F=1.943, P=0.034)$, as shown in Fig. 3. All groups showed a significant decrease in ROM immediately after exercise $(P<0.001)$. KT-24 hr showed significant differences immediately after exercise (KT-24 hr $96.3^{\circ} \pm 14.4^{\circ}$ vs. $\operatorname{CON} 78.1^{\circ} \pm 9.2^{\circ}, P=0.038$ ), at 24 $\mathrm{hr}\left(\mathrm{KT}-24 \mathrm{hr} 106.5^{\circ} \pm 9.5^{\circ}\right.$ vs. CON $\left.89.6^{\circ} \pm 9.6^{\circ}, P=0.033\right)$, and $48 \mathrm{hr}\left(\mathrm{KT}-24 \mathrm{hr} 110.7^{\circ} \pm 7.3^{\circ}\right.$ vs. CON $\left.86.1^{\circ} \pm 13.0^{\circ}, P=0.004\right)$, when compared with CON, while a significant difference at $48 \mathrm{hr}$ (KT-24 hr $110.7^{\circ} \pm 7.3^{\circ}$ vs. KT-post $86.1^{\circ} \pm 13.0^{\circ}, P=0.044$ ) was noticed, when compared with KT-post.

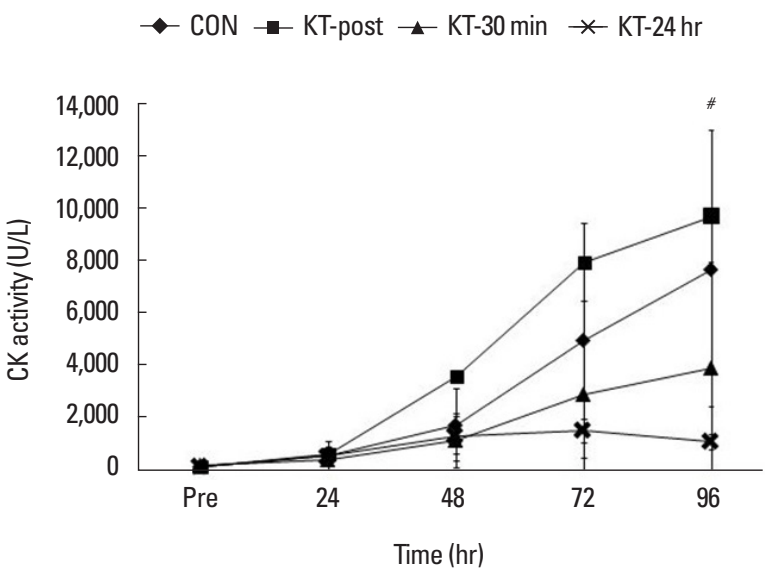

Fig. 4. Changes in creatine kinase (CK) activity following eccentric exercise. Pre, before exercise; CON, no KT application during and after exercise; KT-post, $\mathrm{KT}$ application during exercise and removal immediately after exercise; KT-30 min, KT application during exercise and removal 30 min after exercise; KT-24 $\mathrm{hr}, \mathrm{KT}$ application during exercise and removal $24 \mathrm{hr}$ after exercise. Values are mean \pm standard deviation. ${ }^{~} \mathrm{KT}-24 \mathrm{hr}$ showed lower CK activity at $96 \mathrm{hr}$ $(P<0.05)$ after exercise compared to KT-post.

\section{CK activity}

There were significant group-by-time interactions with $\mathrm{CK}$ activity ( $F=4.247, P=0.043$ ), as shown in Fig. 4. KT-24 hr showed a less increase in CK activity at $96 \mathrm{hr}$ (KT-24 hr 1,080.7 \pm 283.7 $\mathrm{U} / \mathrm{L}$ vs. KT-post 9,759.0 $\pm 9,703.55 \mathrm{U} / \mathrm{L}, P=0.03$ ) after exercise, when compared with KT-post.

\section{DISCUSSION}

KT has been widely used as an ergogenic aid in clinical settings. Previous studies have demonstrated that KT has a positive effect on pain and functional improvement among athletes and patients (Paoloni et al., 2011; Williams et al., 2012). In the present study, we aimed to demonstrate the effect of duration of KT application on MIS, SOR, ROM, and CK activity following eccentric exercise. We found that prolonged application of KT has a positive effect on markers of muscle damage, after eccentric exercise.

MIS is closely related to primary muscle damage after eccentric exercise and is accompanied by morphological changes, such as Z-line streaming, A-band disruption or cytoskeletal disturbance (Proske and Morgan, 2001). Several studies have reported that KT may improve muscular function by reducing abnormal muscle tension (Kase et al., 2003) and muscle strength, by refining muscle alignment (Hsu et al., 2009). Hsu et al. (2009) reported that KT had a significant increase in muscle strength compared to placebo taping group, when the strength of the lower trapezius mus- 
cle among individuals with shoulder impingement syndrome was measured using hand-held dynamometer. Lee et al. (2010) also found that KT application on the flexor muscles around the elbow joint resulted in improved handgrip strength. However, these studies applied KT without inducing muscle damage. A possible explanation that KT improves muscle strength after damaging exercise, may be related to proprioceptive feedback system, in which sensory information is processed in the surrounding muscle tissue, such as muscle spindle that senses abrupt changes in muscle tension and length (Riemann and Lephart, 2002). Several studies reported that reduced force sense was developed by impaired function of proprioceptors following eccentric exercise (Byrne and Eston, 2002; Torres et al., 2010), suggesting that decline in force sense may be related to disturbance of proprioceptive system, including muscle spindle (Brockett et al., 1997). Some studies reported that KT improved the proprioceptive system (Chang et al., 2010; Lin et al., 2011). Chang et al. (2010) found that KT significantly reduced both, absolute and relative force sense error, when compared to placebo taping or no taping. Taken together, it is speculated that KT application may reduce muscle damage, by controlling proprioception, when muscle spindle prevented the overstretched muscle length, by KT during eccentric exercise. However, in the present study, muscle strength in KT-post was significantly different than that in KT-30 min and KT-24 hr, at 48 and $96 \mathrm{hr}$ after exercise and this may be due to application time. Thus, it may be postulated that the longer period of KT application, the more prevention to be lengthened by muscle fibers.

KT also significantly reduced SOR after eccentric muscle contractions in the present study. Several clinical studies have reported that KT may be effective in reducing pain (Karatas et al., 2012; Paoloni et al., 2011). Reduced blood flow occurs under eccentric muscle contractions, although the exact mechanisms are not elucidated (Heap et al., 2006; Kano et al., 2005). In animal models, diameters of arterioles and venules in rat gastrocnemius were significantly reduced after eccentric exercise, when compared to nonexercised control (Heap et al., 2006). Red blood cell hemodynamics, as well as microvascular oxygen pressure were significantly reduced after downhill running in rat spinotrapezius muscle (Kano et al., 2005). A recent human study, also reported that healthy men showed a transient increase in arterial stiffness and impairment of macrovascular function, after damaging exercise (Barnes et al., 2010). In contrast, a recent study by Aguilar-Ferrándiz et al. (2014) reported that KT improved the peripheral venous flow, when measured by venous refill time and venous pump power, as well as perception of pain, among postmenopausal women with chronic venous insufficiency.

Another explanation for KT to reduce SOR may be related to inhibition of nerve activation. It is proposed that KT reduces pressure to the nociceptor situated under the skin (Kase et al., 2003) and attenuates afferent nerve activation, leading to a decreased pain perception (Thelen et al., 2008). However, since the above mechanism is not elucidated by an experimental data, most of KT studies have been relied on this proposed hypothesis. In addition, reduced inflammatory response, a potent factor for SOR following eccentric exercise, may be attributed to reduction in SOR, but again this was not fully demonstrated by experimental data. However, a recent study reported that KT could significantly reduce edema, as well as pain perception after knee replacement surgery (Donec and Kriščiūnas, 2014). Since edema is an indirect marker of inflammation, reduction in edema by KT may be related to blunted inflammation. Again, this needs to be clarified in a further study.

Reduced SOR may affect changes in ROM after eccentric exercise. It is suggested that increase in SOR is related to decrease in ROM (Tokmakidis et al., 2003). A clinical studydemonstrated that KT had a significant reduction in pain, with improved ROM in patients with whiplash injury compared to sham taping group (González-Iglesias et al., 2009). Therefore, in the present study KT significantly decreased SOR in KT-24 hr, resulting in improvement in ROM.

$\mathrm{CK}$ is one of the muscle proteins that leaks into the interstitial spaces by lymphatic system, following eccentric exercise (Sayers and Clarkson, 2003). In the present study, CK activity was significantly lower in KT-24 hr than in KT-post, at $96 \mathrm{hr}$ after eccentric muscle contractions. This may be attributed to increased CK clearance, by improved blood and lymphatic flow after KT application. This mechanism may be related to manual lymph drainage in a rehabilitation setting. The manual lymph drainage technique is known to promote biochemical products in the body by stimulating the lymphatic system (Vairo et al., 2009). Schillinger et al. (2006) reported an experimental group that had undergone manual lymph drainage after treadmill exercise and showed significantly reduced lactate dehydrogenase and aspartate aminotransferase activities, when compared with the control group. Another explanation for decrease in CK activity after KT may be related to reduction in inflammatory response. Myoglobin is a muscle protein that leaks into the circulation after eccentric exercise. A recent study demonstrated that there was a significant correlation between the number of neutrophils and myoglobin levels (Kanda et al., 2013). Like CK activity, myoglobin levels are 
closely related to changes in permeability of cell membrane. Since increase in neutrophils indicates the initiation of an inflammatory response, in the present study, lower CK activity in KT-24 hr may indicate a reduced inflammatory response. Such changes may be related to secondary damage due to eccentric exercise, but it is not clear whether the secondary damage rapidly facilitated those markers or did not occur sufficiently in KT-24 hr. Further research is needed to clarify the exact mechanisms by which $\mathrm{KT}$ attenuated muscle damage.

According to the results of our study, KT should be used in both situations: during exercise and after exercise for up to $24 \mathrm{hr}$, in order to promote faster recovery following eccentric exercise. Furthermore, KT may be a useful technique for physical therapist and athletic trainers in preventing muscle damage and promoting faster recovery from exercise-induced muscle damage.

\section{CONFLICT OF INTEREST}

No potential conflict of interest relevant to this article was reported.

\section{REFERENCES}

Aguilar-Ferrándiz ME, Moreno-Lorenzo C, Matarán-Peñarrocha GA, García-Muro F, García-Ríos MC, Castro-Sánchez AM. Effect of a mixed kinesio taping-compression technique on quality of life and clinical and gait parameters in postmenopausal women with chronic venous insufficiency: double-blinded, randomized controlled trial. Arch Phys Med Rehabil 2014;95:1229-1239.

Barnes JN, Trombold JR, Dhindsa M, Lin HF, Tanaka H. Arterial stiffening following eccentric exercise-induced muscle damage. J Appl Physiol (1985) 2010;109:1102-1108.

Brockett C, Warren N, Gregory JE, Morgan DL, Proske U. A comparison of the effects of concentric versus eccentric exercise on force and position sense at the human elbow joint. Brain Res 1997;771:251-258.

Byrne C, Eston R. The effect of exercise-induced muscle damage on isometric and dynamic knee extensor strength and vertical jump performance. J Sports Sci 2002;20:417-425.

Chang HY, Chou KY, Lin JJ, Lin CF, Wang CH. Immediate effect of forearm Kinesio taping on maximal grip strength and force sense in healthy collegiate athletes. Phys Ther Sport 2010;11:122-127.

Clarkson PM, Hoffman EP, Zambraski E, Gordish-Dressman H, Kearns A, Hubal M, Harmon B, Devaney JM. ACTN3 and MLCK genotype associations with exertional muscle damage. J Appl Physiol (1985) 2005;99:564-569.
Clarkson PM, Sayers SP. Etiology of exercise-induced muscle damage. Can J Appl Physiol 1999;24:234-248.

Connolly DA, Sayers SP, McHugh MP. Treatment and prevention of delayed onset muscle soreness. J Strength Cond Res 2003;17:197-208.

Donec V, Kriščiūnas A. The effectiveness of Kinesio Taping ${ }^{\circledR}$ after total knee replacement in early postoperative rehabilitation period. A randomized controlled trial. Eur J Phys Rehabil Med 2014;50:363-371.

Fu TC, Wong AM, Pei YC, Wu KP, Chou SW, Lin YC. Effect of Kinesio taping on muscle strength in athletes-a pilot study. J Sci Med Sport 2008;11:198-201.

García-Muro F, Rodríguez-Fernández AL, Herrero-de-Lucas A. Treatment of myofascial pain in the shoulder with Kinesio taping. A case report. Man Ther 2010;15:292-295.

Gleeson N, Eston R, Marginson V, McHugh M. Effects of prior concentric training on eccentric exercise induced muscle damage. Br J Sports Med 2003;37:119-125.

González-Iglesias J, Fernández-de-Las-Peñas C, Cleland JA, Huijbregts P, Del Rosario Gutiérrez-Vega M. Short-term effects of cervical kinesio taping on pain and cervical range of motion in patients with acute whiplash injury: a randomized clinical trial. J Orthop Sports Phys Ther 2009;39:515-521.

Heap SJ, Fulgenzi GL, Hudlicka O. Microcirculation in rat soleus muscle after eccentric exercise: the effect of nifedipine. Eur J Appl Physiol 2006;97:687-694.

Howatson G, Hoad M, Goodall S, Tallent J, Bell PG, French DN. Exercise-induced muscle damage is reduced in resistance-trained males by branched chain amino acids: a randomized, double-blind, placebo controlled study. J Int Soc Sports Nutr 2012;9:20.

Hsu YH, Chen WY, Lin HC, Wang WT, Shih YF. The effects of taping on scapular kinematics and muscle performance in baseball players with shoulder impingement syndrome. J Electromyogr Kinesiol 2009;19: 1092-1099.

Huang CY, Hsieh TH, Lu SC, Su FC. Effect of the Kinesio tape to muscle activity and vertical jump performance in healthy inactive people. Biomed Eng Online 2011;10:70.

Kanda K, Sugama K, Hayashida H, Sakuma J, Kawakami Y, Miura S, Yoshioka H, Mori Y, Suzuki K. Eccentric exercise-induced delayed-onset muscle soreness and changes in markers of muscle damage and inflammation. Exerc Immunol Rev 2013;19:72-85.

Kano Y, Padilla DJ, Behnke BJ, Hageman KS, Musch TI, Poole DC. Effects of eccentric exercise on microcirculation and microvascular oxygen pressures in rat spinotrapezius muscle. J Appl Physiol (1985) 2005;99: 1516-1522.

Karatas N, Bicici S, Baltaci G, Caner H. The effect of Kinesiotape application on functional performance in surgeons who have musculo-skele- 
tal pain after performing surgery. Turk Neurosurg 2012;22:83-89.

Kase K, Wallis J, Kase T. Clinical therapeutic applications of the kinesio taping method. Tokyo: Ken Ikai Co. Ltd.; 2003.

Lau WY, Blazevich AJ, Newton MJ, Wu SS, Nosaka K. Assessment of muscle pain induced by elbow-flexor eccentric exercise. J Athl Train 2015;50:1140-1148.

Lee JH, Yoo WG, Lee KS. Effects of head-neck rotation and kinesio taping of the flexor muscles on dominant-hand grip strength. J Phys Ther Sci 2010;22:285-289.

Lee YS, Bae SH, Hwang JA, Kim KY. The effects of kinesio taping on architecture, strength and pain of muscles in delayed onset muscle soreness of biceps brachii. J Phys Ther Sci 2015;27:457-459.

Lin JJ, Hung CJ, Yang PL. The effects of scapular taping on electromyographic muscle activity and proprioception feedback in healthy shoulders. J Orthop Res 2011;29:53-57.

Nicol LM, Rowlands DS, Fazakerly R, Kellett J. Curcumin supplementation likely attenuates delayed onset muscle soreness (DOMS). Eur J Appl Physiol 2015;115:1769-1777.

Ozmen T, Aydogmus M, Dogan H, Acar D, Zoroglu T, Willems M. The effect of kinesio taping on muscle pain, Sprint performance, and flexibility in recovery from squat exercise in young adult women. J Sport Rehabil 2016;25:7-12.

Paoloni M, Bernetti A, Fratocchi G, Mangone M, Parrinello L, Del Pilar Cooper M, Sesto L, Di Sante L, Santilli V. Kinesio Taping applied to lumbar muscles influences clinical and electromyographic characteristics in chronic low back pain patients. Eur J Phys Rehabil Med 2011; 47:237-244.

Proske U, Morgan DL. Muscle damage from eccentric exercise: mechanism, mechanical signs, adaptation and clinical applications. J Physiol 2001;537(Pt 2):333-345.

Riemann BL, Lephart SM. The sensorimotor system, part II: the role of proprioception in motor control and functional joint stability. J Athl Train 2002;37:80-84.

Sayers SP, Clarkson PM. Short-term immobilization after eccentric exercise. Part II: creatine kinase and myoglobin. Med Sci Sports Exerc 2003;35:762-768.

Schillinger A, Koenig D, Haefele C, Vogt S, Heinrich L, Aust A, Birnesser $\mathrm{H}$, Schmid A. Effect of manual lymph drainage on the course of serum levels of muscle enzymes after treadmill exercise. Am J Phys Med Rehabil 2006;85:516-520.

Thelen MD, Dauber JA, Stoneman PD. The clinical efficacy of kinesio tape for shoulder pain: a randomized, double-blinded, clinical trial. J Orthop Sports Phys Ther 2008;38:389-395.

Tokmakidis SP, Kokkinidis EA, Smilios I, Douda H. The effects of ibuprofen on delayed muscle soreness and muscular performance after eccentric exercise. J Strength Cond Res 2003;17:53-59.

Torres R, Vasques J, Duarte JA, Cabri JM. Knee proprioception after exercise-induced muscle damage. Int J Sports Med 2010;31:410-415.

Trombold JR, Reinfeld AS, Casler JR, Coyle EF. The effect of pomegranate juice supplementation on strength and soreness after eccentric exercise. J Strength Cond Res 2011;25:1782-1788.

Vairo GL, Miller SJ, McBrier NM, Buckley WE. Systematic review of efficacy for manual lymphatic drainage techniques in sports medicine and rehabilitation: an evidence-based practice approach. J Man Manip Ther 2009;17:e80-89.

Veqar Z, Imtiyaz S. Vibration therapy in management of delayed onset muscle soreness (DOMS). J Clin Diagn Res 2014;8:LE01-4.

Williams S, Whatman C, Hume PA, Sheerin K. Kinesio taping in treatment and prevention of sports injuries: a meta-analysis of the evidence for its effectiveness. Sports Med 2012;42:153-164.

Yoshida A, Kahanov L. The effect of kinesio taping on lower trunk range of motions. Res Sports Med 2007;15:103-112. 